\title{
Study on Inner Mongolia Tourism Image Based on Content
}

\section{Analysis}

\author{
Zhao Rui \\ School of Management, Inner Mongolia University of Technology, Inner Mongolia China \\ *Corresponding Author: Zhao Rui, School of Management, Inner Mongolia University of Technology, \\ Inner Mongolia China
}

Received Date: 02-07-2017

Accepted Date: 05-07-2017

Published Date: 10-07-2017

\begin{abstract}
With the rapid development of the Internet, more and more information of tourist destination image by means of communication network search tools for tourism consumers, shaping the Internet media on the tourism destination image also plays an increasingly important role. In this paper, based on existing research, by collecting network blog about the tourism image of Inner Mongolia, with the method of content analysis and text mining software -- ROST CM6, to analysis the text has been collected, the tourism image of the Inner Mongolia, so as to explore the defects in tourism image of Inner Mongolia and puts forward the feasible proposal that is conducive to the development of the tourism industry in Inner Mongolia.
\end{abstract}

Keywords: Inner Mongolia; content analysis method; tourism image

\section{INTRODUCTION}

First of all, to obtain the sample data as text analysis. By collecting the major site of blogs as the research data, filtering and sorting to choose the most-viewed in the past five years. After screening, there were more than 110 blogs finally, each blog's words are more than 1200 . Then, using text mining software ROST CM6 to analyze the word frequency of collected texts, screening meaningful high-frequency words, to understand the main features of Inner Mongolia tourism image; then, through the software of "emotion analysis" to analyze the emotion of tourist, and find out the disadvantages of the current overall situation of Inner Mongolia tourism and the existing tourism image.

Analysis of InNer Mongolia Tourism IMAGE BASED ON BLOG TEXT

Statistical Analysis of High Frequency Words

According to the classification of adjectives and nouns, count up the word frequency, with the tools of word frequency analysis and according to the frequency order to select the top 30 . The results are as follows:

According to the statistic results of Table 1, "beautiful", "unique", "best", "comfortable" and "clean" and so on are reflected in the tourist image of Inner Mongolia in the minds of tourists, and descriptions of the features of grasslands, forests, and gourmet foods are more frequent and mostly positive words, shows the positive tourism image of Inner Mongolia. In addition, "beautiful", "unique", "original", "old", "delicious", "clean" and "comfortable" words reflect the different characteristics of Inner Mongolia and other tourist destinations in a certain extent, also showed tourists' recognition and recognition of characteristics of Inner Mongolia tourism. Combining the word frequency results of Table 2, we can learn the tourists' cognitive degree of Inner Mongolia tourism image. Among them, 
Study on Inner Mongolia Tourism Image Based on Content Analysis

"the prairie", "desert", "Mongolia", "nation", "lamb", "forest" are the highly generalization of the Inner

Mongolia tourism image. Grassland is a representative element of tourism in Inner Mongolia, the frequency of the desert and
Mongolian yurt and the vocabulary related to the national culture ranks first. It shows that in the minds of tourists, these elements are the most impressive.

Table1. Inner Mongolia tourism image adjective word frequency ranking table in blog text

\begin{tabular}{|c|c|c|c|c|c|c|c|c|}
\hline Rank & Entry & Frequency & Rank & Entry & Frequency & Rank & Entry & Frequency \\
\hline 1 & beautiful & 82 & 11 & delicious & 16 & 21 & excellent & 13 \\
\hline 2 & unique & 36 & 12 & comfortable & 16 & 22 & relaxed & 11 \\
\hline 3 & difference & 31 & 13 & quietly & 16 & 23 & pretty & 12 \\
\hline 4 & maximum & 35 & 14 & pretty good & 16 & 24 & quaint & 6 \\
\hline 5 & The most beautiful & 26 & 15 & gentle & 10 & 25 & fresh & 11 \\
\hline 6 & Original & 25 & 16 & great & 15 & 26 & wide & 10 \\
\hline 7 & Lush & 11 & 17 & melodious & 11 & 27 & huge & 11 \\
\hline 8 & ancient & 17 & 18 & rich & 12 & 28 & marvellous & 12 \\
\hline 9 & fine & 18 & 19 & clean & 13 & 29 & mighty & 7 \\
\hline 10 & famous & 18 & 20 & Comfort & 13 & 30 & succulent & 6 \\
\hline
\end{tabular}

Note: select the top 30 in the word frequency sorting

Table2. Inner Mongolia tourism image noun frequency rank list in blog text

\begin{tabular}{|c|c|c|c|c|c|c|c|c|}
\hline Rank & Entry & Frequency & Rank & Entry & Frequency & Rank & Entry & Frequency \\
\hline 1 & grassland & 673 & 11 & trip & 65 & 21 & $\begin{array}{c}\text { admission } \\
\text { ticket }\end{array}$ & 46 \\
\hline 2 & desert & 144 & 12 & Obo & 58 & 22 & $\begin{array}{l}\text { master } \\
\text { worker }\end{array}$ & 45 \\
\hline 3 & culture & 122 & 13 & wetland & 54 & 23 & forest & 45 \\
\hline 4 & tourist & 108 & 14 & time & 54 & 24 & characteristic & 45 \\
\hline 5 & Mongolian Yurts & 100 & 15 & scenery & 52 & 25 & friend & 45 \\
\hline 6 & guide & 90 & 16 & mutton & 50 & 26 & camel & 43 \\
\hline 7 & scenic areas & 80 & 17 & square & 50 & 27 & customs & 43 \\
\hline 8 & nation & 80 & 18 & heaven & 48 & 28 & herdsman & 42 \\
\hline 9 & history & 75 & 19 & people & 47 & 29 & blue sky & 41 \\
\hline 10 & scenic spot & 66 & 20 & natural & 47 & 30 & bonfire & 35 \\
\hline
\end{tabular}

Note: select the top 30 in the word frequency sorting

Obo: heaps of stones used by the Mongolians and Tibetans as markings for roads or boundaries

Inner Mongolia Tourism Image Emotional Image Analysis

Using text analysis software to analyze emotion of tourists perception, screening and identifying its emotional color, there are three types of emotions: positive emotions, neutral emotions and negative emotions. Among them, a total of 184 positive emotions, accounting for $63.45 \%$, neutral emotions accounted for 27.24\%, negative emotions accounted for $9.31 \%$ (table 3).By Further analysis, due to the seasonal characteristics of Inner Mongolia tourism is particularly obvious and more tourists in the peak season, tourism facilities and services can not meet all the needs of tourists. 
Table3. Results of sentiment analysis

\begin{tabular}{|c|c|c|}
\hline Emotion category & Blog quantity & Proportion \\
\hline Positive emotion & 184 & $63.45 \%$ \\
\hline Negative emotion & 79 & $27.24 \%$ \\
\hline Neutral mood & 29 & $9.31 \%$ \\
\hline
\end{tabular}

Compared with tourists' positive perception of Inner Mongolia tourism image, the tourists' dissatisfaction with Inner Mongolia tourism is more worthy of attention and reflection. In the negative mood of Table 4 , the dissatisfaction expressed by tourists mainly focuses on the lack of service quality. These deficiencies directly restrict the development of Inner Mongolia tourism. To make the tourism stronger and wider, on the one hand, we should maintain our own advantages, on the other hand, we should make up for the disadvantages as much as possible and repair the short board factors in the process of tourism development. The representative text of the collected negative emotions is shown in the following table.

Table4. Negative emotions blog text table

\begin{tabular}{|c|l|}
\hline Score & \multicolumn{1}{c|}{ Blog Text } \\
\hline 8 & $\begin{array}{c}\text { "The higher the expectation, the greater the disappointment. Apart from a few man-made attractions } \\
\text { worth visiting, almost without a lush place, the bare sand trees rarely see green." }\end{array}$ \\
\hline 1 & $\begin{array}{l}\text { "Dong Ujimqin Banner is a small town, on the prairie, the morning is very quiet and the air is clear, } \\
\text { cold invasion......a group of cattle is moving slowly" }\end{array}$ \\
\hline 14 & $\begin{array}{l}\text { "The tourist management in Inner Mongolia is very confusing, and the quality of tour guides and } \\
\text { drivers is low. I hope the relevant departments and people will pay attention to it." }\end{array}$ \\
\hline
\end{tabular}

In the table, lists the different scores corresponding to the experience of the blog text related to negative mood and tourism, we can find the following problems: part of the problem may be due to individual factors of tourists themselves, including individual physique, tourism experience and tourism attitude etc. There is a part of the problem is the objective factors, such as a net friend referred to the "cold air, cold invasion" does not adapt to climate change, for such cases, the scenic area management staff can improves the meteorological monitoring system in advance to inform visitors, in order to avoid tourists expect higher and greater psychological gap. In addition, tourists have also put forward the problem that the tourist landscape of Inner Mongolia suffered damage during the course of tourism development, which shows that the tourist resources in Inner Mongolia have not been fully utilized and timely protected, and this should be paid attention to by developers. And the basic tourism service facilities are not perfect, and the proper guarantee services are not yet in place. The main cause of these problems lies in the Inner Mongolia local merchants decentralized autonomous management pattern of tourism, low tourist personnel quality, low service quality and lack of service consciousness are the main reason, but the government's lack of attention to service security and mismanagement are the reasons can not be ignored.

\section{RESEARCH CONCLUSIONS}

This paper takes Inner Mongolia tourism image as the research object, and uses text mining content analysis method to analyze network text, and has achieved good research results. The main conclusions are as follows:

1. From the emotional analysis, we can see that the positive sources of the tourist image in Inner Mongolia do not include two basic categories---the infrastructure and services of 
Inner Mongolia tourism. These two kinds of resources are rarely mentioned in the network text, which reflects that the relevant departments or tourist areas in Inner Mongolia have not paid due attention to the improvement of their own tourism infrastructure and the improvement of their service quality.

2. The folk culture in Inner Mongolia tourism has gradually become the focus of attention. Unique ethnic customs is a major feature of Inner Mongolia's tourist culture. The folk cultural elements gradually become one of the representatives of the Inner Mongolia tourism image, and in the same grassland tourism competition to gain greater competitive advantage, it needs to excavate the local tourist products with folk characteristics, to highlight the local personality and characteristics of Inner Mongolia, and improves its competitiveness.

3. The government should increase support and strengthen management. The perfect image of Inner Mongolia tourism and the overall development of Inner Mongolia tourism, if only rely on the efforts of local practitioners, it is difficult to scale. Therefore, relevant departments should give support, and by making laws and regulations to set the rights and obligations for tourism in Inner Mongolia, intensify publicity to promote the grassland tourism culture. Only in this way can grassland tourism culture be able to thrive in a safe and legal environment.

\section{REFERENCE}

[1] Vytautas Janonis, Aistè Dovalienè. Relationship of Brand Identity and Image[J]. Engineering Economics, 2007(1):69.

[2] Saila Saraniemi. Destination brand identity development and value system[J].Tourism Review, 2010, 65 (2):52-56.

[3] Hee Youn Kim, Ji-Hwan Yoon. Examining national tourism brand image: content analysis of Lonely Planet Korea[J].Tourism Review, 2013, 68 (2):56-71.

[4] Xia Huali. On the construction and innovation of tourism destination brand -Taking Enshi tourism development as an example[J].Three Gorges forum version of the theory(The literature of the Three Gorges, 2013) (2): 33-36.

[5] Wang Yuanyuan. Construction and dissemination of tourism destination brand based on demand orientation. Take Qingdao West Coast international tourism resort as an example[J]. Journal of Qingdao Technical College, 2014,27 (2): 10-13.

[6] Jia Lei. Research on Tourism perceived image of Chengdu based on network content analysis [D]. master's degree thesis of Southwestern University, 2014.

\section{AUTHOR'S BIOGRAPHY}

Zhao Rui is a student with master's degree of Inner Mongolia University of Technology. She comes from China .Her major is Tourism. Her research directions are tourism management and planning.

Citation: Zhao Rui, Study on Inner Mongolia Tourism Image Based on Content Analysis, International Journal of Research Studies in Science, Engineering and Technology. 2017;4(5):13-16

Copyright: (C) 2017 Zhao Rui. This is an open-access article distributed under the terms of the Creative Commons Attribution License, which permits unrestricted use, distribution, and reproduction in any medium, provided the original author and source are credited. 